Gut, 1989, 30, 503-509

Liver, biliary, and pancreas

\title{
Measurement of normal portal venous blood flow by Doppler ultrasound
}

\author{
H S BROWN, M HALLIWELL, M QAMAR, A E READ, J M EVANS, \\ AND P N T WELLS
}

From the Department of Medical Physics, Bristol and Weston Health Authority, and the Department of Medicine, University of Bristol, Bristol

SUMMARY The volume flow rate of blood in the portal vein was measured using a duplex ultrasound system. The many errors inherent in the duplex method were assessed with particular reference to the portal vein and appropriate correction factors were obtained by in vitro calibration. The effect of posture on flow was investigated by examining 45 healthy volunteers in three different positions; standing, supine and tilted head down at $20^{\circ}$ from the horizontal. The mean volume blood flow in the supine position was $864(188) \mathrm{ml} / \mathrm{min}$ (mean 1SD). When standing, the mean volume blood flow was significantly reduced by $26 \%$ to $662(169) \mathrm{ml} / \mathrm{min}$. There was, however, no significant difference between flow when supine and when tilted head down at $20^{\circ}$ from the horizontal.

Volume blood flow rate in deep abdominal vessels may be measured using an ultrasound duplex system. This technique has been used to measure blood flow in the superior mesenteric artery ${ }^{2}$ and the portal vein..$^{3-11}$ The aim of this study was to characterise and measure portal venous blood flow in a group of normal Caucasian subjects, to determine the effect of posture and to define and quantify the inherent errors.

B A C K G ROUN D

The volume flow rate $\mathrm{Qa}$ in blood vessel can be calculated by multiplying the cross-sectional area of the blood vessel by the mean velocity of the blood within it.

$$
\mathrm{Q}=\mathbf{v} \times \mathbf{A}
$$

The cross-sectional area $(A)$ is determined from the ultrasonic image of the vessel. The mean velocity $(v)$ can be obtained by Doppler ultrasound either from the maximum velocity or from the power spectrum.

(a) Maximun velocity method

The mean velocity can be obtained from the maximum velocity providing the velocity profile across

Address for correspondence: Professor A E Read, Dept. of Medicine, Bristo Royal Infirmary, Bristol BS2 $8 \mathrm{HW}$.

Accepted for publication 26 August 1988. the vessel is known. For example, if the profile is parabolic, the mean velocity is half the maximum velocity. ${ }^{3}$

In a Doppler system, maximum velocity $\mathrm{V}_{\max }$ is given by equation

$$
V_{\max }=\frac{\Delta f_{\max } \cdot c}{2 f \cdot \cos \theta}
$$

where $f$ is the transmitted frequency of ultrasound, $c$ the speed of sound in soft tissue, $\theta$ the angle of inclination of the ultrasound beam to the direction of blood flow and $\Delta f_{\text {max }}$ the maximum Doppler shift frequency.

\section{(b) Power spectrum method}

The mean velocity can be calculated from the first moment of the power spectrum. ${ }^{11}$ The power spectrum of backscattered Doppler signals is determined using fast Fourier transform analysis. This method relies on uniform insonation across the vessel and laminar flow within the vessel but does not require that the velocity profile is parabolic.

\section{Methods}

PATIENTS

Doppler ultrasound measurement of portal venous 
Table 1

\begin{tabular}{llll}
\hline \multicolumn{1}{c}{ Total } & Men & Women \\
\hline Volunteers $(\mathrm{n})$ & 45 & 26 & 19 \\
Average age $(\mathrm{yrs})$ & $36(11)$ & $37(11)$ & $35(11)$ \\
Age range $(\mathrm{yrs})$ & $18-58$ & $18-58$ & $21-58$ \\
Average height $(\mathrm{m})$ & $1.71(0.08)$ & $1.76(0.05)$ & $1.66(0.077)$ \\
Average weight $(\mathrm{kg})$ & $67.4(10 \cdot 4)$ & $71.7(9 \cdot 7)$ & $62.1(8 \cdot 8)$ \\
Average body & & & \\
surface area' $(\mathrm{m})$ & $1.83(0.20)$ & $1.92(0 \cdot 19)$ & $1.72(0 \cdot 15)$ \\
\hline
\end{tabular}

All results are expressed as the mean (ISD).

blood flow was carried out on 45 healthy volunteer subjects -26 men and 19 women in the age range 1858 years (Table 1). The subjects were studied fasting using a duplex machine (ATL 500 Squibb Medical Systems) comprising a real time mechanical sector scanner associated with a $3 \mathrm{MHz}$ pulsed Doppler flowmeter. The imaging and Doppler systems utilise a single scanhead. A longitudinal image of the portal vein was obtained from cither a subcostal or intercostal approach and the sample volume cursor was then positioned at the centre of the vein lumen, midway between the confluence of the splenic and superior mesenteric veins and its division into left and right hepatic branches (Fig. 1). The image was then 'frozen' and the Doppler system activated by a footswitch. The Doppler shift signals were displayed (Fig. 2) and an appropriate segment stored digitally in the memory of a microcomputer. The mean velocity of the blood was determined from the first moment of the power spectrum.

The cross-sectional area of the portal vein was obtained from a transverse scan at the site from which the velocity samples were taken. As the portal vein is not cylindrical (Fig. 3), a single anterior-posterior

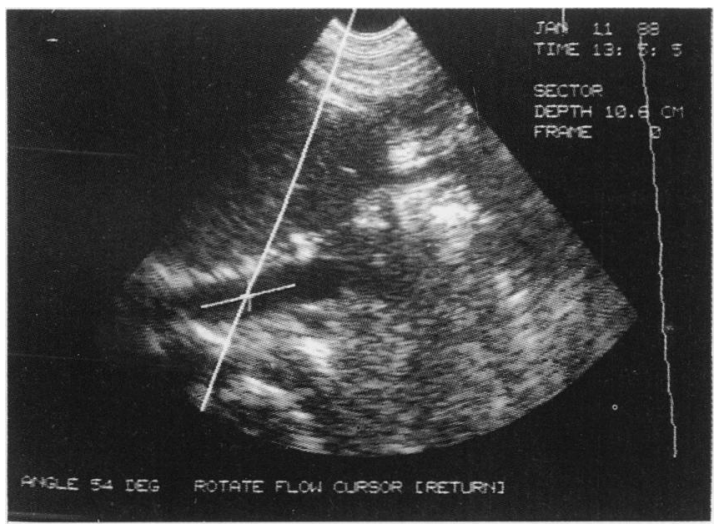

Fig. 1 Longitudinal ultrasound image of the portal vein. On-screen cursor has been positioned by the operator to pass through the range gate site and aligned with the vessel axis.

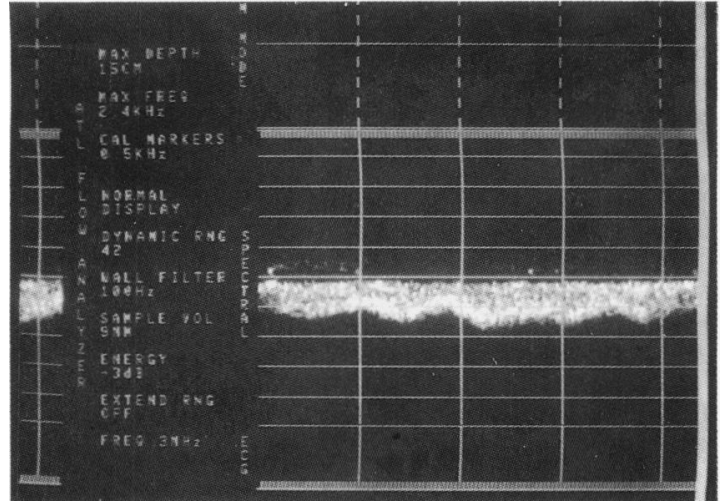

Fig. 2 Typical Doppler spectra from the portal vein. Flow is away from the transducer. Spectra are of uniform amplitude (brightness) and show minimal velocity fluctuations at the cardiac rate.

diameter was not sufficient. Two mutually perpendicular axes were measured from a frozen real time image using the on screen calipers. The image was made as large as possible and the receiver gain reduced to increase visibility of the lumen. The crosssectional area of the vessel was calculated assuming that it was ellipsoidal. The angle between the ultrasonic beam and the longitudinal axis of the vessel was measured directly from the frozen real time image using the on-screen cursor (Fig. 1). If possible this angle was $<60^{\circ}$ for all Doppler measurements.

After determination of portal venous blood flow rate in the supine position further records were obtained with the patient standing upright and in a $20^{\circ}$ head down position relative to the horizontal, on a tilting table.

In each position, between three and six readings

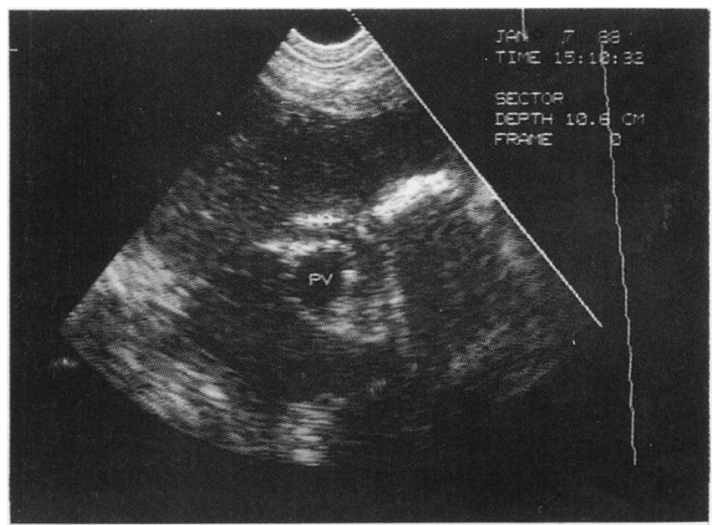

Fig. 3 Cross-sectional image of the portal vein $(P V)$. The hepatic artery $(H A)$ is seen anteriorly. Note that the portal vein has an elliptical cross-section. 
Table 2 Flow rig measurements

\begin{tabular}{lll}
\hline $\begin{array}{l}\text { Pipe diameters } \\
(\mathrm{mm})\end{array}$ & $\begin{array}{l}\text { Linear regression } \\
(\mathrm{ml} / \mathrm{min})\end{array}$ & $\begin{array}{l}\text { Coefficient } \\
\text { ofcorrelation })\end{array}$ \\
\hline $7.9 \times 7.9$ & $1 \cdot(09 \mathrm{X}+59$ & 0.999 \\
$10 \cdot 0 \times 10 \cdot 0$ & $1 \cdot 14 \mathrm{X}+117$ & 0.997 \\
$12 \cdot 7 \times 12 \cdot 7$ & $1 \cdot 23 \mathrm{X}+91$ & 0.998 \\
$13 \cdot 0 \times 17 \cdot 0$ & $1 \cdot 25 \mathrm{X}+162$ & 0.996 \\
$15 \cdot 4 \times 15 \cdot 4$ & $1 \cdot 42 \mathrm{X}+110$ & 0.989 \\
\hline
\end{tabular}

Linear regressions of duplex measured flow against timed collection flow, using a $9 \mathrm{~mm}$ sample volume.

were obtained during a 30 minute rest period in the appropriate position. Subjects in whom at least three readings were not obtained were excluded from the study. The orthogonal dimensions of the portal vein were measured several times from transverse scans in each of the three positions.

The short term and day to day reproducibility of the technique was assessed in two volunteers over five days. Each volunteer was scanned in the same position, each morning, after over night fasting. Six measurements were taken each day over a 30 minute period and averaged.

IN VITRO CALIBRATION

A flow rig comprising a horizontal tube immersed in a water tank and connected to a constant head reservoir was used in the calibration of the system. Absolute flow measurements were made by timed collection of the fluid after its passage along the horizontal tube. Various tubes could be fitted to the flow rig and in this study five of differing dimensions were used. The fluid used was a water based mixture of glycerol and sephadex which had ultrasonic backscattering characteristics similar to those of human blood. The ultrasound scan head was clamped at a position where a maximum length of the tube was visualised and the angle of insonation was $58^{\circ}$. A $9 \mathrm{~mm}$ long sample volume was then used to obtain Doppler shift frequency spectra. The flow was adjusted to give a similar mean velocity range as found in vivo (6-26 $\mathrm{cm} / \mathrm{s}$ ). Errors caused by non-uniform insonation and the wall filter were quantified using this model.

A tissue equivalent phantom was used to evaluate the accuracy of the on-screen distance calipers and angle measuring cursor.

\section{Results}

Results are expressed as the mean (1 standard deviation) of the mean and were compared using Student's $t$-test at the 0.05 level of significance.

The results from the flow rig are shown in Table 2 as linear regressions of the form:

$$
\mathrm{Q}=\mathrm{mQ}_{\mathrm{T}}+\mathrm{k}
$$

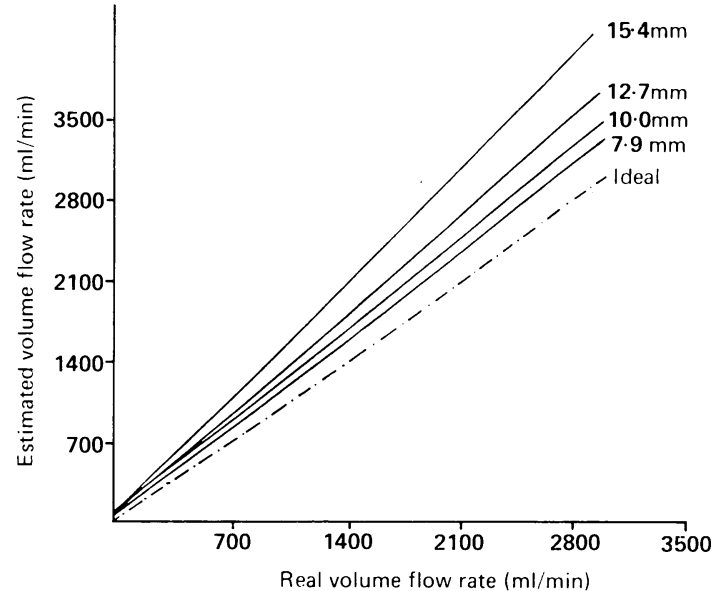

Fig. 4 Regression lines for duplex flow versus timed collection flow in the flow rig. As the pipe diameter is reduced the effects of incomplete insonation decrease and the regression line approaches the true flow values.

where $\mathrm{Q}=$ measured volume flow rate, $\mathrm{Q}_{\mathrm{T}}=$ true volume flow rate,

$\mathrm{m}$ is the slope and $\mathrm{k}$ is the constant offset. The slopes of the linear regressions varied with the diameter of the tube, however, the constant offsets did not vary with tube diameter.

Because the duplex system was shown to be overestimating the mean volume flow rates, it was necessary to use the regressions to correct the in vivo measurements. A graph of the variation of the slopes of the regressions with tube diameter was drawn (Fig. 5 ), with the best fit determined by eye. This enabled the in vivo measurements to be corrected according to the anterioposterior diameter:

$$
\mathrm{Q}_{\mathrm{PV}}=\frac{\mathrm{Q}-\mathrm{k}}{\mathrm{m}}
$$

where $\mathrm{Q}=$ measured volume flow rate,

$\mathrm{Q}_{\mathrm{PV}}=$ true portal vein volume flow rate,

$\mathrm{m}$ is the slope and depends on the anterio-posterior diameter and $\mathrm{k}=94 \mathrm{ml} / \mathrm{min}$. The accuracy of the system calipers was found to be better than $1 \mathrm{~mm}$. The angle measuring cursor was accurate to within $\pm 1^{\circ}$.

The short term reproducibility determined by examining two volunteers for 30 minutes on five consecutive days was found to be approximately $11 \%$. The day to day reproducibility was taken as the variation in the average daily measurement and was $8 \%$.

It was not possible to obtain flow rate measurements from all the volunteers mainly because the portal vein was obscured in some by abdominal gas and an appropriate angle of insonation could not be 


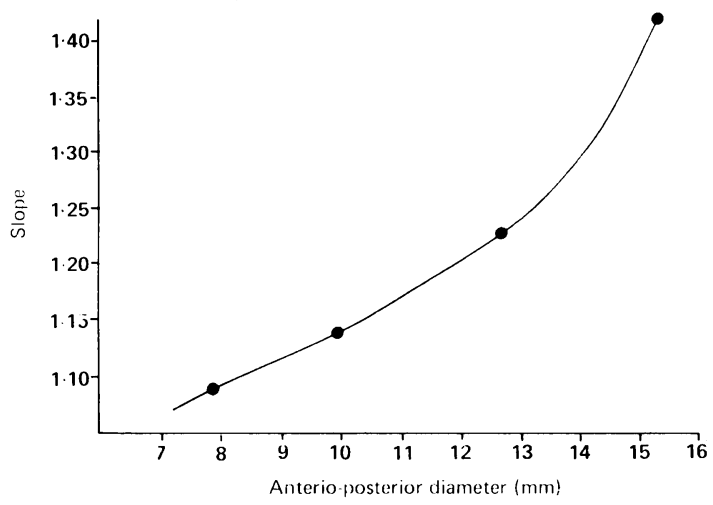

Fig. 5 Correction curve to compensate for the effects of incomplete insonation. A correction factor was obtained from this curve for each portal vein anterioposterior diameter.

obtained. Supine flow could be measured in $78 \%$ of the group. Erect flow measurements were successful in $89 \%$. In only $11 \%$ was it impossible to obtain any measurement. Supine portal venous blood flow rate in 35 volunteers (16 men and 19 women) was 864 (188) $\mathrm{ml} / \mathrm{min}$ (Table 3 ). There was no significant difference between the sexes in the mean volume flow rate normalised for body weight.

There was no significant difference between the mean volume flow rate in the supine and head down positions, but the mean volume flow rate in the erect position was $26 \%$ less than in the supine position (Fig. 6).

The changes in volume flow rate were associated with changes in cross-sectional area of the vessel. The mean velocity of blood in the portal vein did not change significantly. The average cross-sectional area decreased from $1 \cdot 13(0 \cdot 27) \mathrm{cm}^{2}$ in the supine

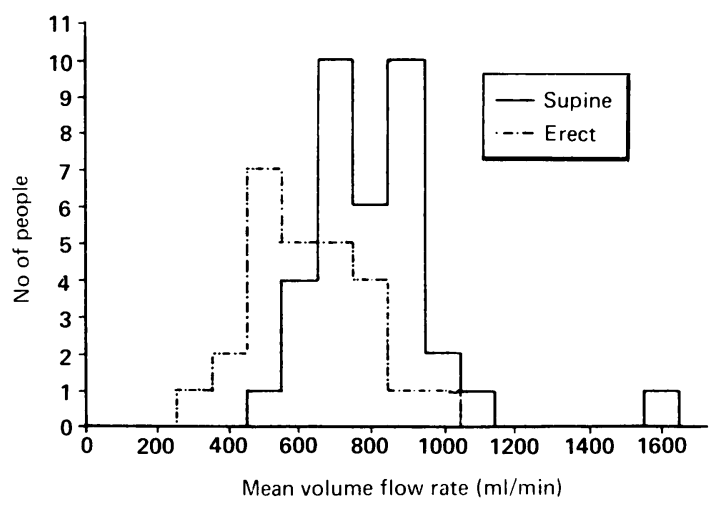

Fig. 6 Histograms of the portal vein volume flow rate for the supine and erect positions. The erect mean value is $26 \%$ less than the supine mean value.

position to $0 \cdot 87(0 \cdot 31) \mathrm{cm}^{2}$ in the erect position - a decrease of $23 \%$.

\section{Discussion}

This paper reports the investigation of portal venous blood flow rate in normal Caucasian subjects. This technique has been used in Japanese subjects ${ }^{3.74}$ and, allowing for differences in body size, has produced similar figures for basal blood flow in the portal vein.

The results show that posture has an effect on portal flow rate and indicate that basal portal venous flow rate is maximal in the supine position. In the erect position the flow rate is reduced by $26 \%$. It seems likely that this reduction is a consequence of the fall in cardiac output that follows assumption of the vertical position..$^{12}$ This position results in venous pooling in the legs and a fall in right auricular filling

Table 3 Portal blood flow in subjects in supine, erect and head down positions

\begin{tabular}{|c|c|c|c|c|c|c|c|}
\hline $\begin{array}{l}\text { In vivo } \\
\text { Results }\end{array}$ & $\begin{array}{l}\text { Volunteers } \\
(n)\end{array}$ & $\begin{array}{l}\text { Cross sect } \\
\text { area } \\
\left(\mathrm{cm}^{2}\right)\end{array}$ & $\begin{array}{l}\text { Mean velocity } \\
(\mathrm{cm} / \mathrm{s})\end{array}$ & $\begin{array}{l}\text { Max velocity } \\
(\mathrm{cm} / \mathrm{s})\end{array}$ & $\begin{array}{l}\text { Mean } \\
\text { volume flow } \\
(\mathrm{ml} / \mathrm{min})\end{array}$ & $\begin{array}{l}\text { Mean volume flow/ } \\
\text { unit body weight } \\
(\mathrm{ml} / \mathrm{min} / \mathrm{Kg})\end{array}$ & $\begin{array}{l}\text { Mean volume flow/ } \\
\text { unit body surface area } \\
\text { (ml/min/m }\end{array}$ \\
\hline \multicolumn{8}{|l|}{ Men } \\
\hline Supine & 16 & $1 \cdot 27(0 \cdot 23)$ & $11.08(2 \cdot 51)$ & $28 \cdot 7(5 \cdot 2)$ & $847(138)$ & $12 \cdot 32(2 \cdot 01)$ & $458(75)$ \\
\hline Head down & 13 & $1 \cdot 31(0 \cdot 19)$ & $10 \cdot 46(1.85)$ & $26 \cdot 7(3 \cdot 2)$ & $823(144)$ & $12 \cdot 10(2 \cdot 15)$ & $446(73)$ \\
\hline Erect & 13 & $1.00(0.25)$ & $12 \cdot 43(3 \cdot 74)$ & $29 \cdot 2(7 \cdot 0)$ & $715(176)$ & $10 \cdot 20(2 \cdot 50)$ & $380(91)$ \\
\hline \multicolumn{8}{|l|}{ Women } \\
\hline Supine & 19 & $1 \cdot 01(0 \cdot 25)$ & $14 \cdot 40(5 \cdot 63)$ & $34 \cdot 3(9 \cdot 0)$ & $878(225)$ & $14 \cdot 31(3 \cdot 64)$ & $511(125)$ \\
\hline Head down & 16 & $1 \cdot 06(0 \cdot 23)$ & $12 \cdot 94(3 \cdot 08)$ & $30 \cdot 9(5 \cdot 3)$ & $837(193)$ & $13.67(3 \cdot 32)$ & $492(110)$ \\
\hline Erect & 14 & $0.75(0.30)$ & $15 \cdot 26(4 \cdot 81)$ & $34 \cdot 6(8 \cdot 6)$ & $613(150)$ & $9 \cdot 74(2 \cdot 24)$ & $358(87)$ \\
\hline \multicolumn{8}{|l|}{ Total } \\
\hline Supine & 35 & $1 \cdot 13(0 \cdot 27)$ & $12 \cdot 32(5 \cdot 90)$ & $31 \cdot 7(7 \cdot 9)$ & $864(188)$ & $13 \cdot 45(3 \cdot 20)$ & $487(107)$ \\
\hline Head down & 29 & $1.17(0.25)$ & $11.83(2.86)$ & $29 \cdot 0(4.9)$ & $831(170)$ & $12.97(2.92)$ & $472(97)$ \\
\hline Erect & 27 & $0.87(0.31)$ & $13.90(4.49)$ & $32 \cdot 0(8 \cdot 2)$ & $662(169)$ & $9.98(2 \cdot 33)$ & $368(88)$ \\
\hline
\end{tabular}

All results expressed as the mean (one standard deviation) 
pressure and cardiac output. This fall in cardiac output is followed by increased sympathetic activity with compensatory vasoconstriction ${ }^{1314}$ and an increase in heart rate. These mechanisms give incomplete compensation and the fall in cardiac output may amount to $2 \cdot 2 / 1 \mathrm{~min}$ compared with the supine position. The fall in portal venous flow of $26 \%$ is in keeping with the measured fall in cardiac output in standing subjects. There is thus a further clinical rationale for nursing patients with acute and chronic liver disease supine in bed.

Before this technique can be incorporated in routine clinical work, the errors intrinsic to the method $^{1516}$ need to be delineated and corrections made. The major errors are discussed below. The major errors in the mean velocity derived from the power spectrum are the result of (a) non-uniform insonation, (b) the presence of a high pass wall thump filter, (c) the limited frequency discrimination of the spectrum analyser.

\section{(a) Non-uniform insonation}

With a centrally sited sample volume, incomplete insonation leads to the loss of important information concerning blood flow nearest the vessel walls. Near the walls the blood flow is slower and if this information is omitted the mean velocity is over estimated. ${ }^{17}$ It is important to account for this error and correction factors derived from flow rig studies seem appropriate.

Each duplex system should be calibrated before quantitative measurements are made.

\section{(b) High pass wall thump filter}

There is an error inherent in the processing of the Doppler signals due to the filtering out of low frequencies from vessel wall movement. For some equipment this filter can be removed but this was not possible in this study. The calibration of the duplex system against the flow rig, however, incorporated this systemic error.

\section{(c) Frequency discrimination of spectrum analyser}

The output of the spectrum analyser has a finite number of discrete frequency intervals $(37.5 \mathrm{~Hz})$. This results in a limited frequency resolution. For a typical mean Doppler shift of $250 \mathrm{~Hz}$, this can lead to a random error in velocity of the order of $7 \%$, although this would be less for higher velocities.

An important source of error in the mean velocity derived from maximum velocity concerns the assumption that the velocity profile of blood flow in the portal vein is parabolic. The course of the portal vein is variable, the vessel is of variable diameter and is formed by the junction of two major veins. For these reasons the flow profile cannot be assumed to be parabolic, although some investigators have considered this to be the case. ${ }^{3}$

ANGLE OF INSONATION

The Doppler shift frequency depends on the velocity of blood in the direction of the interrogating beam. Accurate measurement of the angle of insonation is critical and becomes difficult if there is only a short stretch of vessel available or if the image is of poor quality. For example, an error of $3^{\circ}$ at $58^{\circ}$ can lead to a $9 \%$ error in cosine $58^{\circ}$ and hence a $9 \%$ random error in the mean velocity. The angle of insonation should be kept below $60^{\circ}$ whenever possible.

\section{A REA}

The measurement of the cross-sectional area of the portal vein is probably the largest single source of error. The difficulty in obtaining a precise measurement lies in the resolution of the ultrasound scanner. It was estimated that the anterioposterior diameter could be measured to within $1 \mathrm{~mm}$ and the lateral diameter to within $2 \mathrm{~mm}$. Thus for a typical crosssectional area of $(10.9 \times 13.0) \pi / 4$, errors of the order of $16-20 \%$ could be expected.

Apart from these sources of error which depend on the method of measurement used a number of other technical difficulties arose.

\section{Intestinal gas}

Gas in the upper abdomen often obscured the portal vein making it particularly difficult or impossible to measure the cross-sectional area.

\section{Turbulent (non-laminar) flow}

Turbulence was a feature in some normal subjects when lying supine. Further, it could be minimised by lying the patient on the left side. Presumably this must mean that the portal vein can be compressed by abdominal viscera or pressure from the operator of the scanner.

\section{Cardiac and respiratory fluctuations}

Fluctuations in the Doppler spectrum which coincided with both the respiratory and cardiac cycle were noticed. The respiratory fluctuations were due to the mechanical movement of the vessel through the sample volume, thus only the maximal parts of the Doppler spectrum should be included in the analysis. The cardiac fluctuations, however, were more likely to be true fluctuation in the velocity, and presumably volume flow rate. Thus these fluctuations should be averaged over several cardiac cycles.

Apart from the ultrasonic duplex system, the only technique presently available for the direct measurement of volume flow rate in the portal vein involves exposure of the vein at laparotomy and application 
of electromagnetic flowmasters. ${ }^{18}$ Most clearance methods measure total hepatic flow - that is, portal venous and hepatic arterial flows together, though multiple vascular catheter techniques ${ }^{19}$ do allow separate measurement of total hepatic flow and portal flow. The substances used include bromsulphalein (BSP), indocyanine green ${ }^{20}$ and radioactive xenon. ${ }^{19}$ All clearance methods are invasive and this seriously limits the clinical usefulness of such studies.

The duplex system has been shown to produce reliable results in vitro and its application to the in vivo situation has resulted in volume flow rate measurements which are in line with expected values. It is possible to identify the major sources of error and provide suitable correction procedures. Combining the errors discussed previously results in a volume flow rate figure which has an overall random error contribution of about $20 \%$ in any individual measurement.

The size of random error means that one estimation from an individual may not be clinically useful. The observation of relative changes after physiological stimuli is, however, feasible using this technique. If a population is studied then changes of less than $20 \%$ can be monitored as the error is random and therefore the true mean is approached as the population size increase.

The method is rapid, reproducible and allows for serial measurements to be made non-invasively. It is thus suitable for use as a physiological measurement tool as well as clinically for patients with portal hypertension due to intra- or extra-hepatic obstruction.

The effect of posture on portal venous blood flow rate has been shown. Future work will include the measurement of changes due to the ingestion of food and various gastrointestinal hormones.

A duplex ultrasound system has been used to determine the portal venous blood flow in a group of 45 normal subjects. The mean portal blood flow was $864(188) \mathrm{ml} / \mathrm{min}$ at rest in the supine position and this was reduced by $26 \%$ in the vertical position. The errors inherent in this method are described and the possible application of the technique to clinical and physiological situations is discussed.

The authors are indebted to all the volunteers in this study, especially those from the Sun Alliance Insurance Group.

\section{References}

1 Qamar MI, Read AE, Skidmore R, Evans JM, Wells PNT. Transcutaneous Doppler ultrasound measurement of superior mesenteric artery blood flow in man. Gut 1986; 27: 100-5.

2 Sato S, Ohnishi K, Sugita S, Okuda K. Splenic artery and superior mesenteric artery blood flow: nonsurgical Doppler US measurement in healthy subjects and patients with chronic liver disease. Radiology 1987; 164: 347-52.

3 Moriyasu F, Ban N, Nishida O, et al. Clinical application of an ultrasonic Duplex system in the quantitative measurement of portal blood flow. J Clin Ultrasound 1986; 14: 579-88.

4 Moriyasu F, Ban N, Nishida O, et al. Portal hemodynamics in patients with hepatocellular carcinoma. Radiology 1986; 161: 707-11.

5 Ohnishi K, Saito M, Nakayama T, et al. Portal venous hemodynamics in chronic liver disease: effects of posture change and exercise. Radiology 1985; 155: 757-61.

6 Okazaki K, Miyazaki M, Onishi S, Ito K. Effects of food intake and various extrinsic hormones on portal blood flow in patients with liver cirrhosis demonstrated by pulsed Doppler with the Octoson. Scand J Gastroenterol 1986; 21: 1029-38.

7 Miyazaki M, Okazaki K, Sakamoto Y, et al. Measurement of portal blood flow in the patients with obstructive jaundice using a pulsed Doppler system. Acta Hepatol J 1986; 27: 1598-605.

8 Zoli M, Marchesini G, Cordiani MR, et al. EchoDoppler measurement of splanchnic blood flow in control and cirrhotic subjects. J Clin Ultrasound 1986; 14: 429-35.

9 Tsujimoto F, Uchiyama M, Tada S. Noninvasive detection of the portal vein flow with Duplex ultrasound method. Proc WFUMB '85 Ultrasound Med Biol 1985; 70: [Suppl].

10 Smith HJ, Grottum P, Simonsen S. Ultrasonic assessment of abdominal venous return. Effect of cadiac action and respiration on mean velocity pattern, crosssectional area and flow in the inferior vena cava and portal vein. Acta Radiol (Diagn) (Stockh) 1985; 26: 581-8.

11 Gill RW. Performance of the mean frequency Doppler demodulator. Ultrasound Med Biol 1979; 5: 237-47.

12 Bevegard S, Holmgren A, Jonsson B. The effect of body position on the circulation at rest and during exercise with special reference to the influence on the stroke volume. Acta Physiol Scand 1960; 49: 279-98.

13 Wood JE, Eckstein JW. A tandem forearm plethysmograph for study of acute responses of the peripheral veins of man: the effect of environmental and local temperature change and the effects of pooling blood in the extremities. J Clin Inv 1958; 37: 41-56.

14 Page EB, Hickman JB, Sieker HO, et al. Reflex venomotor activity in normal persons and in patients with postural hypotension. Circulation 1955; 11: 26270.

15 Evans DH. Can ultrasonic Duplex scanners really measure volumetric flow? In: (Evans JA Ed.) Institute of Physical Sciences in Medicine, Physics in medical ultrasound 145-54. London: 1987.

16 Bertram CD. Blood flow measurement -fundamentals of the problem. Aus Phys Eng Sci in Med 1987; 10: 26-30.

17 Gill RW. Measurement of blood flow by ultrasound: accuracy and sources of error. Ultrasound Med Biol 1985: 11: 625-41. 
18 Price JB, Britton RC, Peterson LM, et al. The validity of chronic hepatic blood flow measurements obtained by electromagnetic flowmeter. J Surg Res 1965; 5: 313-5.

19 Strandell T, Erwald R. Kulling KG, Lundbergh P, Marions O, Wiechel KL. Measurement of dual hepatic blood flow in awake patients. J Appl Physiol 1973; 35: 755-61.

20 Caesar J, Shaldon S, Chiandussi L, et al. The use of indocyanine green in the measurement of hepatic blood flow as a test of hepatic function. Clin Sci 1961; 21: 43-7. 